\title{
AVALIAÇÃO DA ATIVIDADE DE PUNICA GRANATUM LINNAEUS CONTRA Staphylococcus aureus ISOLADOS DE MASTITE BOVINA E AÇÃO ANTI-INFLAMATÓRIA “in vivo"
}

\author{
Lauana Aparecida SANTOS ${ }^{1}$ \\ Juliana da Silva MENEZES ${ }^{2}$ \\ Luciana Rosa Alves RUFINO ${ }^{3}$ \\ Nelma de Mello Silva OLIVEIRA ${ }^{4}$ \\ João Evangelista FIORINI ${ }^{5}$ \\ ${ }^{1}$ Acadêmica do Curso de Biomedicina, Universidade José do Rosário Vellano. email: lauanexsantos@hotmail.com \\ ${ }^{2}$ Aluna de Mestrado em Ciência Animal, Universidade José do Rosário Vellano. \\ ${ }^{3}$ Técnica de Laboratório da Universidade José do Rosário Vellano. \\ ${ }^{4}$ Médica Veterinária, Professora da Universidade José do Rosário Vellano. \\ ${ }^{5}$ Farmacêutico, Professor da Universidade José do Rosário Vellano.
}

Recebido em: 14/04/2014 - Aprovado em: 30/06/2014 - Disponibilizado em: 30/07/2014

\begin{abstract}
RESUMO
O uso de plantas com finalidade terapêutica, tem ampla aceitação popular motivando as investigações científicas. A romã (Punica granatum L.) é pertencente à família Punicaceae, sendo popularmente utilizada para tratar vários problemas de saúde. O presente estudo avaliou seus possíveis efeitos inibitórios contra Staphylococcus aureus isolados de casos de mastite bovina e ação anti-inflamatória "in vivo". O extrato foi preparado utilizando a casca do fruto de Punica granatum. A avaliação da atividade antimicrobiana foi realizada em teste de difusão de ágar, com 16 cepas de $S$. aureus isolados. Foi realizado o ensaio de edema de pata induzido por carragenina em ratos Wistar, machos. O extrato da casca do fruto em todas as concentrações testadas inibiu todos os microrganismos isolados e também demonstrou redução do edema de pata nas concentrações testadas de 81,$25 ; 162,50 ; 325$ e $650 \mathrm{mg} / \mathrm{mL}$. Os resultados deste estudo podem explicar em parte a utilização de $P$. granatum para o tratamento de doenças infecciosas e inflamatórias podendo contribuir para a alternativa terapêutica em Medicina Veterinária.

Palavras chave: Punica granatum. Atividade antimicrobiana. Atividade anti-inflamatória. Fitoterapia. Plantas medicinais.

\section{Evaluation of the activity of Punica granatum Linnaeus against Staphylococcus aureus isolated from bovine mastitis and anti-inflammatory action "in vivo"}

\begin{abstract}
ABSTRAT
The use of plants for therapeutic purposes, has broad popular acceptance motivating scientific research. The pomegranate (Punica granatum L.) pertecent is the Punicacae family, is used populary for several treat health problems. The present study evaluated their possible inhibitory effects against Staphylococcus aureus isolates from cases of bovine mastitis and anti-inflammatory "in vivo" action. The extract was using prepared of the Punica granatum fresh fruit. The antibiotic activity was evaluated by the agar diffusion method on 16 isolates $S$. aureus strains. Testing of paw edema induced by carrageenan in rats was performed, males. The extract fresh fruit pericarp in the all inhibition concentration tests all isolated microorganisms and too reduction demonstrated of paw edema in the tested concentrations of 81,$25 ; 162,50 ; 325$ and $650 \mathrm{mg} / \mathrm{mL}$. The results of the study may partly explain the use $P$. granatum for the treatment of inflammatory and infectious diseases may contribute to alternative therapy in veterinary medicine. Keywords: Punica granatum. Antimicrobial activity. Anti-inflammatory activity. Herbal Medicine. Medicinal plants.

\section{Introdução}

A planta Punica granatum L. é

pertencente à família Punicaceae e na

medicina popular é conhecida como romã, romeira, romãzeira, romeira da granada entre outros, sendo esta muito utilizada como planta frutífera, ornamental de parques e jardins. A
\end{abstract}


romã é uma planta originária da região do Oriente Médio; a árvore cresce em regiões áridas e a produção de seu fruto se dá no período de fevereiro a setembro. A composição química do suco da fruta é constituída de compostos fenólicos como antocianinas, delfinidina, cianidina, pelorgodina, quercetina e ácidos fenólico, cafeíco, catequínico, clorogênico, orto e para cumárico, elágico, gálico e taninos (punicalagina) (MARTINS, 1995; JARDINI e FILHO, 2007).

A romãzeira é popularmente utilizada para tratar vários problemas de saúde, predominando as doenças gastrointestinais. O suco é utilizado contra úlceras na boca e gengivas, dores de ouvido, tratamento de dispesia e disenteria. Suas flores são usadas para o tratamento de gengivas, prevenindo a perda dentária (WERKMAN et al., 2008).

A mastite é a infermidade de maior frequência no gado leiteiro, tendo como agentes etiológicos principalmente Streptococcus agalactiae e Sthaphylococcus aureus. Caracaterísticas como a virulência de S. aureus contribuem para a resistência deste microrganismo no tecido mamário. Vale ressaltar também que o uso inadequado de antibióticos no tratamento pode gerar o surgimento de cepas microbianas resistentes (MEDEIROS et al., 2009). Os medicamentos fitoterápicos começam a ganhar cada vez mais espaço no tratamento veterinário, tanto de parasitoses como bacterioses (ZAFALON; FILHO; OLIVEIRA e RESENDE, 2007).

A introdução de novos medicamentos no mercado requer inúmeros estudos. Dentre os ensaios laboratoriais destacam-se os testes para avaliação da atividade anti-inflamatória, utilizando o teste de edema de pata para avaliar estas reações, pois o edema justifica-se ser um dos sinais cardeais da inflamação. Desta forma, o objetivo desta pesquisa foi avaliar a atividade antimicrobiana contra $S$. aureus isolados de casos de mastite bovina e ação antiinflamatória "in vivo" da planta $P$. granatum.

\section{Materiais e métodos}

\subsection{Coleta das espécimes}

Os frutos de Punica granatum foram coletados no município de Alfenas, estado de Minas Gerais, Brasil, à beira da Rodovia MG - 179, Km 0, no mês de agosto de 2012 e identificados. A exsicata do vegetal está armazenada no Herbário da Universidade José do Rosário Vellano (UNIFENAS), Alfenas, sob o $n^{\circ} 352$.

\subsection{Obtenção do extrato}

O extrato da casca do fruto de Punica granatum foi obtido utilizando-se como agente extrator álcool etílico a 70\%, conforme a técnica descrita por Caceres et al., (1995) e Farmacopeia Brasileira $5^{\mathrm{a}}$ edição (2010). As romãs foram abertas e seu conteúdo interno foi retirado. Foram pesados $400 \mathrm{~g}$ da casca do 
fruto e colocados em $1600 \mathrm{~mL}$ de álcool a $70 \%$. Essa mistura foi macerada em balão volumétrico $(2000 \mathrm{~mL})$ e armazenada à temperatura ambiente por 15 dias, ao abrigo da luz. Após, o mesmo foi filtrado e mantido sob refrigeração a $4^{\circ} \mathrm{C}$ em frasco âmbar estéril. Posteriormente, foi concentrado em evaporador rotatório e liofilizado. Na hora do uso, o mesmo foi ressuspenso em água destilada estéril e passado em filtro Millipore ${ }^{\circledR}(0,22 \mu \mathrm{m})$.

\subsection{Aquisição de amostras de animais infectados}

Os animais portadores de mastite foram identificados utilizando-se testes como o da caneca de fundo preto e o CMT (California Mastit Test), para clínica e subclínica respectivamente. Antes da coleta, efetuou-se a higienização das mãos do ordenhador e dos tetos das vacas, com solução de água e sabão; em seguida, os tetos foram secos com papel toalha descartáveis. Coletou-se 32 amostras de $25 \mathrm{~mL}$ de leite em frascos estéreis identificados, realizadas imediatamente antes da ordenha e foram examinadas vacas em diferentes estágios de lactação. As 32 amostras foram acondicionadas em caixas isotérmicas, transportadas sob refrigeração e encaminhadas ao Laboratório de Biologia e Fisiologia de Microrganismos, UNIFENAS, Alfenas, MG.

\subsection{Exames microbiológicos}

As amostras foram semeadas em Ágar Baird Parker, enriquecido com gema de ovo + telurito de potássio, e incubadas a $37^{\circ} \mathrm{C}$ por 24 horas. Após o período de incubação, observou-se o crescimento e a morfologia das colônias. Estas foram caracterizadas como Staphylococcus spp por análise morfológica e bacterioscopia, empregando-se o método de coloração de Gram.

Após análise morfológica, as amostras foram submetidas a testes bioquímicos para a identificação da espécie Staphylococcus aureus (provas de catalase, manitol, coagulase e DNAse) conforme Machado (2006) .

\subsection{Estudo da atividade antimicrobiana da casca da romã}

As linhagens foram cultivadas em caldo nutritivo (BHI- Brain Heart Infusion DIFCO); incubadas a $37{ }^{\circ} \mathrm{C}$ por $24 \mathrm{~h}$. Foi avaliada a atividade antimicrobiana do extrato vegetal de $P$. granatum realizando-se o teste de difusão em ágar, Concentração Inibitória Mínima (CIM) e Concentração Microbicida Mínima (CMM), de acordo com os padrões do National Commitee for Clinical Laboratory Standards (NCCLS, 2002). Foram utilizadas as concentrações de 10,15; 20,$31 ; 40,62 ; 81,25 ; 162,50 ; 325 ; 650$ e 1300 $\mathrm{mg} / \mathrm{mL}$. As determinações do perfil de sensibilidade foram realizadas de acordo com a metodologia de microdiluição em caldo 
Mueller Hinton para bactérias, conforme protocolo M7A6 (CLSI, 2003). Os ensaios foram realizados em duplicata.

\subsection{Avaliação da atividade anti-inflamatória}

Foram utilizados ratos Wistar (170-50 g) machos provenientes do Biotério central da UNIFENAS. Os animais foram mantidos em gaiolas plásticas com ração e água ad libitum em temperatura ambiente. Oito horas antes da realização dos experimentos os animais foram privados de ração. Os protocolos utilizados foram aprovados pelo Comitê de Ética na Experimentação Animal (CEEA) desta Instituição (processo nº. 08A/2012).

2.7 Teste do edema de pata induzido por carragenina em ratos

O edema de pata foi induzido pela injeção de $0,1 \mathrm{~mL}$ de carragenina $(1 \% \mathrm{p} / \mathrm{v})$ administrada na região subplantar da pata direita de ratos Wistar machos $(n=6 / 6$ grupos); na pata esquerda administrou-se 0,1 $\mathrm{mL}$ de solução salina. Uma hora antes da injeção de carragenina, o extrato hidroalcoólico de $P$. granatum, solubilizado em salina estéril, foi administrado, por via oral, nas doses de 650, 325, 162,5 e 81,25 $\mathrm{mg} / \mathrm{kg}$ (WINTER et al., 1962). O grupo controle negativo recebeu $0,5 \mathrm{~mL} / \mathrm{kg}$ de indometacina por via oral. Após, as patas foram aferidas pelo equipamento pletismômetro (Ugo Basile modelo FF34) antes da aplicação da substância próinflamatória, e de hora em hora, durante $5 \mathrm{~h}$. Após a aplicação do estímulo, a medida do edema foi feita pela diferença entre o volume deslocado da pata direita e o volume deslocado da pata esquerda. A indometacina $10 \mathrm{mg} \cdot \mathrm{kg}^{-1}$ foi usada como fármaco de referência.

\section{Resultado}

Dentre as 32 amostras analisadas, provenientes de animais portadores de mastite identificados com casos clínicos e subclínicos da região agropecuária de Alfenas, MG, 16 amostras apresentavam S. aureus. Após a realização do teste de atividade antimicrobiana, foi observado sensibilidade a todas as concentrações testadas 10,15;20,31; 40,$62 ; 81,25 ; 162,50 ; 325 ; 650$ e 1300 $\mathrm{mg} / \mathrm{mL}$.

$\mathrm{Na}$ verificação da atividade antimicrobiana, observou-se a formação de halos de inibição entre 21 a $30,5 \mathrm{~mm}$ em todas as cepas isoladas de $S$. aureus (Tabela 1). Os resultados obtidos, na Concentração Inibitória Mínima (CIM) e Concentração Microbicida Mínima (CMM), foram positivos para todas as cepas microbianas em concentrações variadas de $P$. granatum (Tabela 1). 
Tabela 1 - Halos de Inibição, Concentração Inibitória Mínima e Concentração Microbicida Mínima do extrato hidroalcoólico da casca de $P$. granatum

\begin{tabular}{|c|c|c|c|}
\hline Microrganismo & $\begin{array}{c}\text { Halos de Inibição } \\
\left(\mathrm{mm}^{3}\right)\end{array}$ & $\begin{array}{l}\mathrm{CIM}^{*}(\mathrm{mg} / \mathrm{mL} \text { do } \\
\text { extrato) }\end{array}$ & $\begin{array}{l}\mathrm{CMM}^{* *}(\mathrm{mg} / \mathrm{mL} \text { do } \\
\text { extrato) }\end{array}$ \\
\hline Amostra 1 & 30,5 & 325 & 650 \\
\hline Amostra 2 & 24 & 40,62 & 325 \\
\hline Amostra 3 & 26 & 40,62 & 325 \\
\hline Amostra 4 & 26 & 20,31 & 162,5 \\
\hline Amostra 5 & 25,5 & 10,15 & 325 \\
\hline Amostra 6 & 26,5 & 40,62 & 325 \\
\hline Amostra 7 & 25,5 & 10,15 & 325 \\
\hline Amostra 8 & 21 & 10,15 & 325 \\
\hline Amostra 9 & 24 & 650 & 650 \\
\hline Amostra 10 & 24,5 & 20,31 & 162,5 \\
\hline Amostra 11 & 29,5 & 325 & 325 \\
\hline Amostra 12 & 27 & 20,31 & 162,5 \\
\hline Amostra 13 & 23 & 81,25 & 162,5 \\
\hline Amostra 14 & 25 & 20,31 & 162,5 \\
\hline Amostra 15 & 24,5 & 20,31 & 162,5 \\
\hline Amostra 16 & 26,5 & 40,62 & 162,5 \\
\hline
\end{tabular}

Fonte: $\mathrm{O}$ autor

O tratamento com diferentes comportaram de forma semelhante a partir da concentrações $(650,322,162,5$ e 81,25 $2^{\mathrm{a}}$ hora de experimento. A redução do $\mathrm{mg} / \mathrm{Kg}$ ) do extrato de $P$. granatum inibiu a processo edematogênico nos grupos de inflamação induzida por carregenina no pico máximo da $3^{\mathrm{a}}$ hora como mostra a Figura 1. As concentrações de 162,5 e $81,25 \mathrm{mg} / \mathrm{Kg}$ do animais tratados com as diferentes concentrações do extrato foi observada em todos. 
Figura 1 - Efeito da administração v.o do extrato de Punica granatum (650, 325, 162, 5 e 81,25 mg. $\left.\mathrm{Kg}^{-1}\right)$ e induzido por carragenina (10 mg. $\left.\mathrm{Kg}^{-1}\right)$ sobre o edema de pata. ${ }^{-*}$ Significativo após a análise da variância (ANOVA) seguido do teste de Tukey $(\mathrm{p}<0,05)$.



Fonte: $\mathrm{O}$ autor

\section{Discussão}

Nas últimas décadas, os fitofármacos têm assumido um papel importante como meio terapêutico alternativo devido ao aumento significativo da ocorrência de microrganismos resistentes aos antimicrobianos (WERKMAN et al., 2008). A atividade inbitória e anti-inflatória pode ser atribuída a combinação de principios ativos presentes na planta.

Silva et al., (2008) realizaram a atividade antimicrobiana do extrato da casca do fruto de Punica granatum sobre 38 linhagens de $S$. aureus de origem bovina para a determinação da Concentração Inibitória Mínima (CIM). Os microrganismos testados com este extrato apresentaram sensibilidade formando halos de inibição variando de 10 a 36 mm de diâmetro, apresentando resultados semelhantes a este estudo podendo-se confirmar a eficiência do extrato de $P$. granatum como alternativa terapêutica na Medicina Veterinária.

Recentemente observou-se que a punicalagina, um tanino elágico derivado do fruto da romanzeira, é provavelmente um dos principais constituintes antimicrobianos desta fruta (MACHADO et al., 2003). Os taninos têm efeito inibitório sobre bactérias e fungos. Existem três hipóteses para o mecanismo de ação antimicrobiana. A primeira pressupõe a inibição das enzimas de bactérias e fungos e/ou a complexação dos substratos as enzimas; a segunda seria a ação dos taninos sobre as membranas celulares dos microrganismos, modificando o seu metabolismo (MELLO e SANTOS, 2002). Por ultimo, a terceira menciona a complexação dos taninos com íons metálicos, diminuindo, a disponibilidade destes elementos essenciais para o metabolismo dos microrganismos. 
Machado et al., (2003) realizou estudos avaliando o potencial antimicrobiano de 14 extratos de plantas tradicionais brasileiras no tratamento de doenças infecciosas frente a microorganismos de importância médica e multi-resistentes. Extratos de $P$. granatum foram eficazes contra cepas de $S$ aureus. Braga et al. (2005) verificaram in vitro que o extrato da romã também inibiu o crescimento de $S$. aureus, dependente da concentração dos extratos.

Os extratos de plantas são geralmente uma mistura de compostos ativos e inativos e suas atividades antimicrobianas, antiinflamatórias e antioxidantes devem ser interpretados com critérios. Vale ressaltar que o local, período e tipos de solventes utilizados na extração dos princípios ativos podem interferir na atividade biológica do extrato (MELO et al., 2012).

A atividade antimicrobiana dos extratos de Origanum vulgare, Thymus vulgaris, Lippia graveolens, Zingiber officinale, Salvia officinalis, Rosmarinus officinalis e Ocimum basilicum foi avaliada, utilizando 32 isolados de Staphylococcus spp, oriundos de rebanhos leiteiros bovinos, onde observaram a CIM para todos os extratos testados em diferentes concentrações (POZZO et al., 2011).

Bezerra et al., (2009) realizaram ensaios de ação antimicrobiana sobre 25 isolados de casos de mastite bovina, observando que o extrato de jurema-preta (Mimosa tenuiflora) demonstrou potencial antimicrobiano em diferentes concentrações testadas. Nader et al., (2010) também avaliaram o potencial de atividade antimicrobiana in vitro dos extratos de algumas plantas endêmicas do Cerrado, dentre elas Baccharis dracunculifolia, Cochlospermum regium, Croton antisyphiliticus, Eugenia dysenterica e Lippia sidoides, contra $S$. aureus isolados de leite mastítico. Os resultados demonstraram que os extratos de Baccharis dracunculifolia, Croton antisyphiliticus, seguido do extrato de Lippia sidoides, apresentaram, respectivamente, melhor atividade inibitória sobre Staphylococcus aureus ressaltando a importância de plantas medicinais como recurso terapêutico.

A carregenina promove um processo inflamatório provavelmente mediado por prostaglandinas, apresentando um pico máximo entre 2 e 3 horas após a sua aplicação (ARA et al., 2010). Este dado confirma os resultados observados na Figura 1 comparativamente ao controle positivo. Dessa maneira observa-se que houve a redução de efeito dose-resposta nos edemas por carragenina tratados com o extrato de $P$. granatum.

A redução do edema de pata está relacionada com a interrupção do mecanismo de síntese de prostaglandina (SILVÉRIO et al., 2008). Anteriormente demonstrou-se que o extrato de $P$. granatum é rico em taninos e outros compostos fenólicos. Em processos de cura de feridas, queimaduras e inflamações, os taninos auxiliam formando uma camada protetora (complexo tanino-proteína e/ou 
polissacarídeo) sobre tecidos epiteliais lesionados, podendo, o processo curativo ocorrer naturalmente (MONTEIRO; ALBUQUERQUE e ARAÚJO, 2005). Sendo assim é possível que a presença destes possa ter influenciado na redução do edema assim como o fármaco de referência Indometacina (anti-inflamatório não esteroide).

Dentre os mecanismos envolvidos no efeito anti-inflamatório da romã, estudos realizados demostraram que a mesma é capaz de inibir a ativação de vias inflamatórias incluindo o $\mathrm{NF}-\kappa \mathrm{B}^{3}$. Vale ressaltar que as proantocianidinas e as antocianidinas, princípios ativos isolados da planta, podem inibir a atividade da cicloxigenase e a produção de óxido nítrico (HOU et al., 2003). As elangitaninas podem reduzir a sinalização celular inflamatória em modelos laboratoriais de células de câncer de cólon. O ácido punicico e os polifenóis podem inibir a biosíntese de prostaglandinas (LANSKY et al., 2007). Estima-se que os componentes do suco de romã podem agir de forma sinérgica na supressão da expressão das citocinas inflamatórias (LANSKY et al., 2007).

Em um estudo realizados por Ara et al., (2010) foi verificado que a atividade antiinflamatória do extrato metanólico (400 $\mathrm{mg} / \mathrm{kg}$ ) da planta Adenanthera pavonina L, apresentou 37,10\% de inibição da inflamação na primeira hora do experimento e, o extrato extraído com diclorometano (400 mg/kg) apresentou 33,11\% na inibição da inflamação na terceira hora do experimento, sendo que foi comparável ao resultado da substância de referência diclofenaco sódico.

Silvério et al., (2008) avaliaram a atividade anti-inflamatória da planta Eremanthus erythropappus. O edema de pata foi induzido por carragenina sendo verificado que o mesmo foi reduzido em 23,81\% (100 $\mathrm{mg} / \mathrm{kg}$ ) e $47,62 \%$ (200 mg/kg). Os resultados apresentados indicam que o extrato etanólico de E. erythropappus pode constituir alvo potencial para uso em terapias da dor, inflamação e úlcera.

\section{Conclusão}

A partir destes resultados pode-se sugerir que o extrato hidroalcoólico de Punica granatum possui atividade antimicrobiana em diferentes concentrações sobre S.aureus isolados de casos de mastite bovina e atividade anti-inflamatória, a qual foi dose depende sobre o edema induzido por carragenina.

\section{Agradecimentos}

Ao CNPq pela concessão da bolsa de Iniciação Científica. 


\section{Referências}

ARA, A. et al. Anti-inflammatory activity of Adenanthera pavonina L., Fabaceae, in experimental animals. Rev. Bras. Farmacogn. 2010; 20(6):929-932.

BRAGA, L.C. et al. Pomegranate extract inhibits Staphylococcus aureus growth and subsequent enterotoxin production. Journal of Ethnopharmacology. 2005. v.96, n.1-2, p.3359.

BEZERRA, D.A.C. et al. Atividade biológica da jurema-preta (Mimosa tenuiflora (Wild) Poir.) sobre Staphylococcus aureus isolados de casos de mastites bovina Rev. Bras.

Farmacogn. 2009;19(4):814-817.

CARCERES, A.; MENÉNDEZA, H.; MÉDEZ, E. et al. Antigonorrhoel activity of plants used in Guatemala for the treatment of sexually transmitted diseases. $J$

Etnopharmacol. 1995;48(2):85-8.

Clinical and Laboratory Standards Institute (CLSI) 2003. Methods for dilution antimicrobial susceptibility tests for bacteria that grow aerobically. Approved standard Sixth edition. M7-A6. Wayne, PA, USA: CLSI.

FARMACOPEIA BRASILEIRA. 5th ed. São Paulo: Atheneu; 2010. v. 1-2.

JARDINI, F.A.; FILHO, J.M. Avaliação da atividade antioxidante em diferentes extratos da polpa e sementes da romã (Punica granatum, L.). Rev Ciênc Farm Básica Apl. 2007;43(1).

LANSKY, L.P.; NEWMAN, R.A. Punica granatum (pomenagrate) and its potential for prevention and treatment of inflamtion and cancer. J Etnopharmacol. 2007. 109(2):177206.

HOU, D.X.; OSET, T.; LIN, S. et al. Anthacyanidins induce apotosis in human promyelocytic leukemia cells: Struture activity relations and mechanisms involved. Int J Oncol. 2003. 23:705-712.

MACHADO, T.B. et al. In vitro activity of Brazilian medicinal plants, naturally occurring naphthoquinones and their analogues, against methicillin-resistant Staphilococcus aureus. International Journal of Antimicrobial Agents. 2003. v.21, n.3, p.279-84.

MACHADO, T.R.O. Susceptibilidade a antimicrobianos por cepas de Staphylococcus coagulase-negativa isoladas de leite mastítico bovino proveniente de propriedades leiteiras de 9 estados brasileiros.[Tese]. Jaboticabal, SP: Universidade Estadual Paulista Júlio de Mesquita Filho, Faculdade de Ciências Agrárias e Veterinária, Campus de Jaboticabal; 2006.

MARTINS, E. Plantas medicinais. Viçosa: UFV. 1995;162-163. 
MEDEIROS, E.S. Perfil de sensibilidade

microbiana in vitro de linhagens de

Staphylococcus spp. isolados de vacas com mastite subclínica. Pesq. Vet. Bras.

2009;29(7):569-574.

MELO, M.S.F; ROCHA, C.Q; SANTOS, M.H. et al. Pesquisa de bioativos com atividade antimicrobiana nos extratos hidroetanólicos do fruto, folha e casca de caule do Zizyphus joazeiro mart. Revista da Universidade Vale do Rio Verde, Três Corações. 2012. v. 10, n. 2, p. 43-51.

MELLO, CP; SANTOS, SC. Taninos. In: Farmacognosia: da planta ao medicamento. Organizadopor Cláudia Maria Oliveira Simões et al. 4 ed. Porto Alegre /

Florianópolis: Editora Universitária / UFRGS /Ed. da UFSC. 2002. pp. 950.

MONTEIRO JM, Albuquerque UP e Araújo EL. Taninos: Uma abordagem da química à ecologia. Quim. Nova. 2005;28(5):892-896.

NADER TT, et al. Avaliação in vitro da eficácia de extratos de plantas medicinais do cerrado frente Staphylococcus aureus isolado de diferentes fontes de propriedades leiteiras. Arq. Inst. Biol. 2010;77(3):429-433.

(NCCLS) National Comitte for Clinical Laboratory Standart. Padrões de desempenho para teste de susceptibilidade antimicrobiana: padrão M2-A6 aprovado, $6^{\mathrm{a}}$ ed. Wayne, PA: NCCLS; 2002.

POZZO MD, et al. Activity of essential oils from spices against Staphylococcus spp. isolated from bovine mastitis. Arq. Bras.

Med. Vet. Zootec. 2011;63(5):1229-1232.

SILVA MAR, et al. Antibiotic activity of the extract of Punica granatum Linn. over bovine strains of Staphylococcus aureus. Rev. Bras. Farmacogn. 2008;18(2):209-212

SILVÉRIO MS, et al. Propriedades farmacológicas do extrato etanólico de Eremanthus erythropappus (DC.) McLeisch (Asteraceae). Rev. Bras. Farmacogn. 2008;18(3):430-435.

ZAFALON LF, FILHO NA, OLIVEIRA JV, REZENDE FD. Mastite subclínica causada por Staphylococcus aureus: custo-benefício da antibioticoterapia de vacas em lactação. Arq. Bras. Med. Vet. Zootec.2007;59(3):577585.

WERKMAN C, et al. Aplicações terapêuticas da Punica granatum L. (romã). Rev. Bras. Pl. Med.2008;10(3):104-111. 